\title{
Large Buffering Effect of the Duodenal Bulb in Duodenal Switch: a Wireless pH-Metric Study
}

\author{
Z Bekhali $^{1,2} \cdot$ J Hedberg $^{1} \cdot$ H Hedenström ${ }^{3} \cdot$ M Sundbom $^{1}$
}

Published online: 7 February 2017

(C) The Author(s) 2017. This article is published with open access at Springerlink.com

\begin{abstract}
Introduction Bariatric procedures result in massive weight loss, however, not without side effects. Gastric acid is known to cause marginal ulcers, situated in the small bowel just distal to the upper anastomosis. We have used the wireless BRAVO $^{\text {TM }}$ system to study the buffering effect of the duodenal bulb in duodenal switch (DS), a procedure in which the gastric sleeve produces a substantial amount of acid.

Methods We placed a pre- and a postpyloric $\mathrm{pH}$ capsule in 15 DS-patients (seven men, 44 years, BMI 33) under endoscopic guidance and verified the correct location by fluoroscopy. Patients were asked to eat and drink at their leisure, and to register their meals for the next $24 \mathrm{~h}$.

Results All capsules but one could be successfully placed, without complications. Total registration time was 17.2 (1.324) hours prepyloric and 23.1 (1.2-24) hours postpyloric, with a corresponding $\mathrm{pH}$ of 2.66 (1.74-5.81) and 5.79 (4.75-7.58), $p<0.01$. The difference in $\mathrm{pH}$ between the two locations was reduced from 3.55 before meals to 1.82 during meals, $p<0.01$. Percentage of time with $\mathrm{pH}<4$ was 70.0 (19.9$92.0)$ and $13.0(0.0-34.6)$ pre and postpylorically, demonstrating a large buffering effect.

Conclusion By this wireless pH-metric technique, we could demonstrate that the duodenal bulb had a large buffering
\end{abstract}

Z Bekhali

zakaria.bekhali@regiongavleborg.se

1 Department of Surgical Science, Upper Gastrointestinal Surgery, Uppsala University, SE-751 85 Uppsala, Sweden

2 Gävle county Hospital, 80188 Gävle, Sweden

3 Department of Medical Science, Clinical Physiology, Uppsala University, SE-751 85 Uppsala, Sweden effect, thus counteracting the large amount of gastric acid passing into the small bowel after duodenal switch. This physiologic effect could explain the low incidence of stomal ulcers.

Keywords Bariatric surgery $\cdot$ Duodenal switch $\cdot$ Marginal ulcer $\cdot \mathrm{pH}$-metry

\section{Introduction}

Compared to conservative methods, bariatric surgery provides sustainable weight loss, high resolution of comorbidities and decreased overall mortality [1]. The development of bariatric surgery has been experimental, and today several different procedures are used. Roux-en-Y gastric bypass (RYGBP) is commonly performed and considered gold standard by many authors [2]. Another procedure, duodenal switch (DS), is used, preferably in patients with super obesity (body mass index, BMI, over $50 \mathrm{~kg} / \mathrm{m}^{2}$ ), and yields remarkable weight loss in this group of patients [3, 4]. DS consists of two different parts. First, a gastric tube is created by preforming a vertical sleeve gastrectomy to reduce the volume of ingested food. The duodenal bulb is divided two to $4 \mathrm{~cm}$ distal to the pylorus and anastomosed to the last $2.5-\mathrm{m}$ of distal ileum (alimentary limb). Second, the remaining small bowel, carrying bile and pancreatic juice, is anastomosed $1 \mathrm{~m}$ from the ileocecal valve, resulting in decreased uptake of ingested nutrients.

All bariatric procedures have side effects because of major changes in gastrointestinal physiology. The connection of stomach and its acid-producing mucosa to the small bowel can result in marginal ulcers, an ulcer situated just distal to the anastomosis. The incidence of marginal ulcer ranges between 0.6 and $16 \%$ after RYGBP [5, 6], while it is substantially less frequent in patients having had DS around $0.3 \%$ [4]. 
As the gastric sleeve in DS contains a much larger amount of acid-producing gastric mucosa than the small gastric pouch in RYGBP, the differences in marginal ulcer incidence could be viewed as paradoxical. The role of included duodenal bulb in this has not been investigated.

Different $\mathrm{pH}$-measuring systems exist, for instance the classic catheter-based technique and the wireless BRAVO ${ }^{\mathrm{TM}}$ capsule. The BRAVO ${ }^{\mathrm{TM}}$ system (Given Imaging, Yokneam, Israel), developed to measure $\mathrm{pH}$ in gastro-esophageal reflux disease, has the advantage of longer registration time [7-10], without disturbing the patient's daily habits. Moreover, intragastric and duodenal $\mathrm{pH}$ monitoring has been implemented with BRAVO ${ }^{\mathrm{TM}}$ system with good reliability and promising results [11-17]. We have previous experience in measuring $\mathrm{pH}$ in the jejunum, just below the level of gastrojejunal anastomosis in RYGBP, where $\mathrm{pH}$ was below four in 10.5 (0.3-37.7) percent of the time during more than $24 \mathrm{~h}$ of continuous registration [18].

The aim of the present study was to study the acidity above and below the duodenoileostomy in DS by measuring pre- and postpyloric $\mathrm{pH}$ during $24 \mathrm{~h}$ of normal activity.

\section{Materials and Methods}

Fifteen patients (seven men, 44 (25-56) years, BMI 33 (2541) $\mathrm{kg} / \mathrm{m}^{2}$ ) who had undergone DS more than 1 year earlier were recruited at our center. All patients were free of abdominal symptoms and medication, except one patient in whom PPI-treatment for gastro-esophageal reflux was discontinued 2 weeks before the study. The study was performed at our endoscopic unit in November 2011-February 2014. A written consent was obtained from all participants.

After a fasting period of at least $6 \mathrm{~h}$, a cannula was put in the patient's right arm and a blood sample taken for Helicobacter pylori and f- serum gastrin. Prior to upper endoscopy, two wireless BRAVO ${ }^{\mathrm{TM}}$ capsules were calibrated and diazepam offered as sedative. With the patient lying on the left side, the delivery system of the first capsule was inserted transorally and followed by the endoscope, to allow direct visual control. To enhance passage through the pylorus, the soft tip of delivery system was grasped by an endoscopic snare. The capsule was placed $1-2 \mathrm{~cm}$ below the duodenoileostomy and fastened to the mucosa according to the manufacturer's instructions, i.e., activating the locking pin after $1 \mathrm{~min}$ of suction with $550 \mathrm{mmHg}$, (Fig.1). After removing the delivery system and endoscope, the prepyloric capsule was placed in the same way, $5 \mathrm{~cm}$ oral to pylorus. The correct placement of the capsules was confirmed by fluoroscopy with patient lying in the supine position (Fig.2). The wireless $\mathrm{pH}$ recording was activated and patients were asked to carry the portable receiver in a band over the shoulder. Patients were also asked to press a specific button on the receiver whenever ingesting something and to record the meal in a paper protocol. During the 24-h registration, patients were encouraged to eat at their leisure. The location of the capsules was verified by repeated fluoroscopy when the patient returned the recording device on the following day.

$\mathrm{pH}$ data was uploaded to the Polygram NET version 4.2 (Given Imaging, Yokneam, Israel). Sudden change in the $\mathrm{pH}$ curve with consistently neutral pattern or loss of signal indicated the detachment of the capsule (Fig.2). The total registration time before the detachment of the capsule, median $\mathrm{pH}$ during the total registration time, percentage of time with $\mathrm{pH}<4$, as well as $\mathrm{pH} 30 \mathrm{~min}$ immediately before and during meals, were registered. The difference in mean $\mathrm{pH}$ before and during meals was then calculated. All measurements were performed individually by two examiners, and discussed if any inconsequence occurred.

\section{Statistics}

Results are presented as median and range, unless otherwise specified. Mean $\mathrm{pH}$ pre and postpylorically was calculated during the whole time of registration for each patient. Time of registration, $\mathrm{pH}$, mean percentage of time with $\mathrm{pH}<4$ and difference in $\mathrm{pH}$ before and during meals were compared using Wilcoxon matched-pair signed rank test. A $p$ value $<0.05$ was considered significant. Statistical analyses were performed by using GraphPad Prism 5.0f (GraphPad Software, Inc., USA).

\section{Results}

All capsules, except one postpyloric capsule, could be successfully placed and the correct location was verified by fluoroscopy. No complications occurred, nor were any complications reported during the $\mathrm{pH}$-registration.

There was no significant difference in registration time preand postpylorically (17.2 vs. $23.1, p=0.36)$. A lower $\mathrm{pH}$ was seen in the gastric tube compared to the postpyloric site, 2.66 (1.74-5.81) vs. 5.79 (4.75-7.58), $p<0.01$. When calculating percentage of time with $\mathrm{pH}<4$, the same difference in acidity was apparent, $70.0 \%(19.9-92.0)$ and $13.0 \%(0.0-34.6)$, respectively, $p<0.01$. The difference in $\mathrm{pH}$ between the two locations was reduced from 3.55 before meals to 1.82 during meals, $p<0.01$ (Table 1, Fig. 3).

Serology for $H$ pylori was negative in all patients. Serum gastrin varied between $<10$ and $28 \mathrm{pmol} / \mathrm{L}$ (reference interval $<55$ ), and was thus within normal interval in all patients. No correlation was seen to the measured $\mathrm{pH}$ levels. 


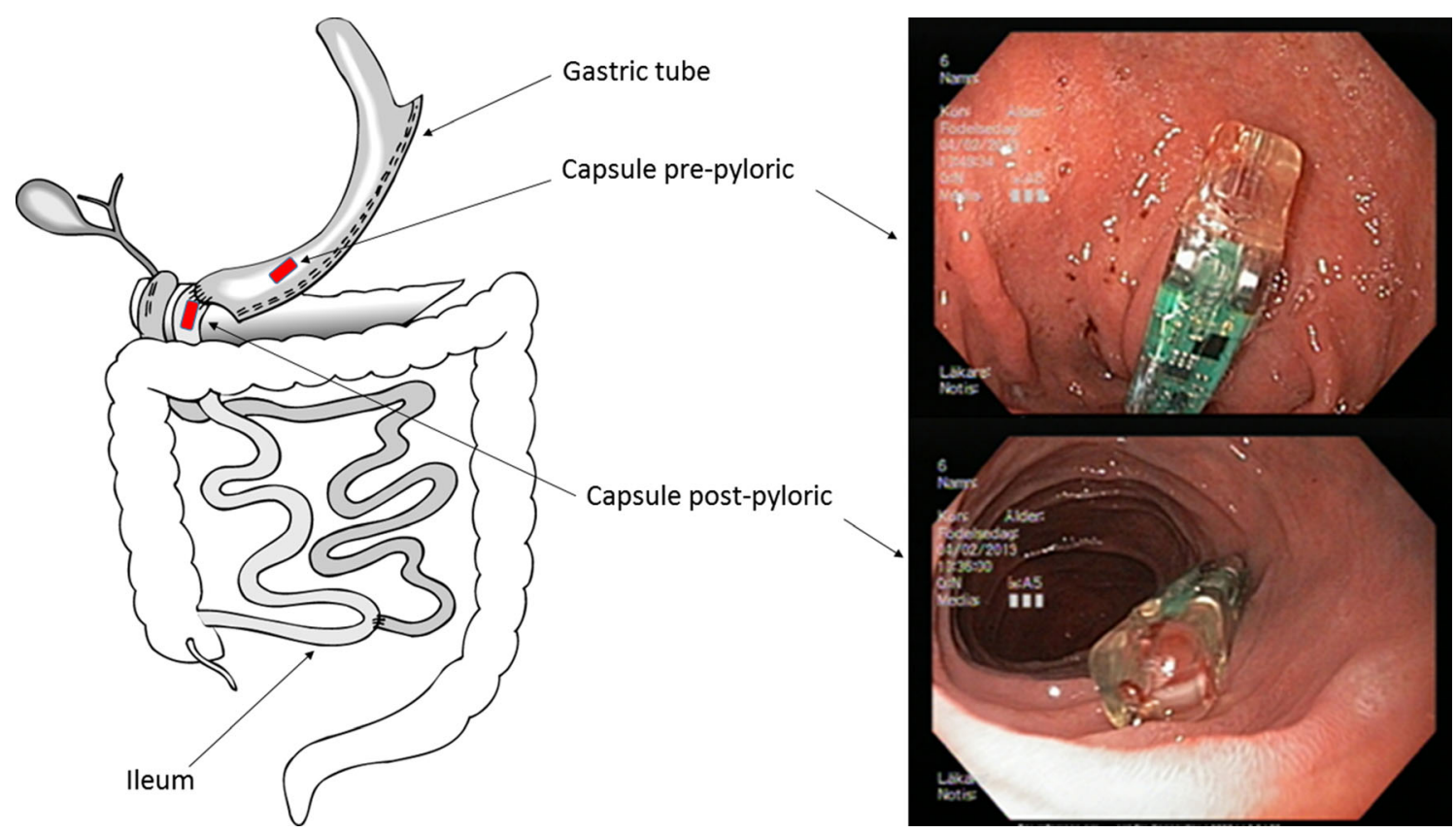

Fig. 1 Schematic drawing of duodenal switch (DS) with marked positions for the two Bravo capsules. Endoscopic images representing capsules in place at the pre and postpyloric site

\section{Discussion}

In this $\mathrm{pH}$-metric study, we could demonstrate that the duodenal bulb has a large buffering effect. Physiologically, this seems to counteract the large amount of acid-producing mucosa in DS. As expected, the difference between pre- and postpyloric $\mathrm{pH}$ was reduced during meals, when ingested food increased the gastric $\mathrm{pH}$.
Although conventional placement of the BRAVO ${ }^{\mathrm{TM}}$-capsule is done after removal of the endoscope, we used direct endoscopic guidance to place the two capsules. Direct placement avoids a repeated endoscopy to confirm the placement of the capsule and is associated with shorter procedure time and less discomfort for the patients $[8,12,19]$. An acute angulation of the gastric tube imposed some difficulties in advancing the capsule distally through the pylorus, and the use of an

Fig. 2 Confirmation by

fluoroscopy after placement of the two Bravo capsules and a typical $\mathrm{pH}$ curve

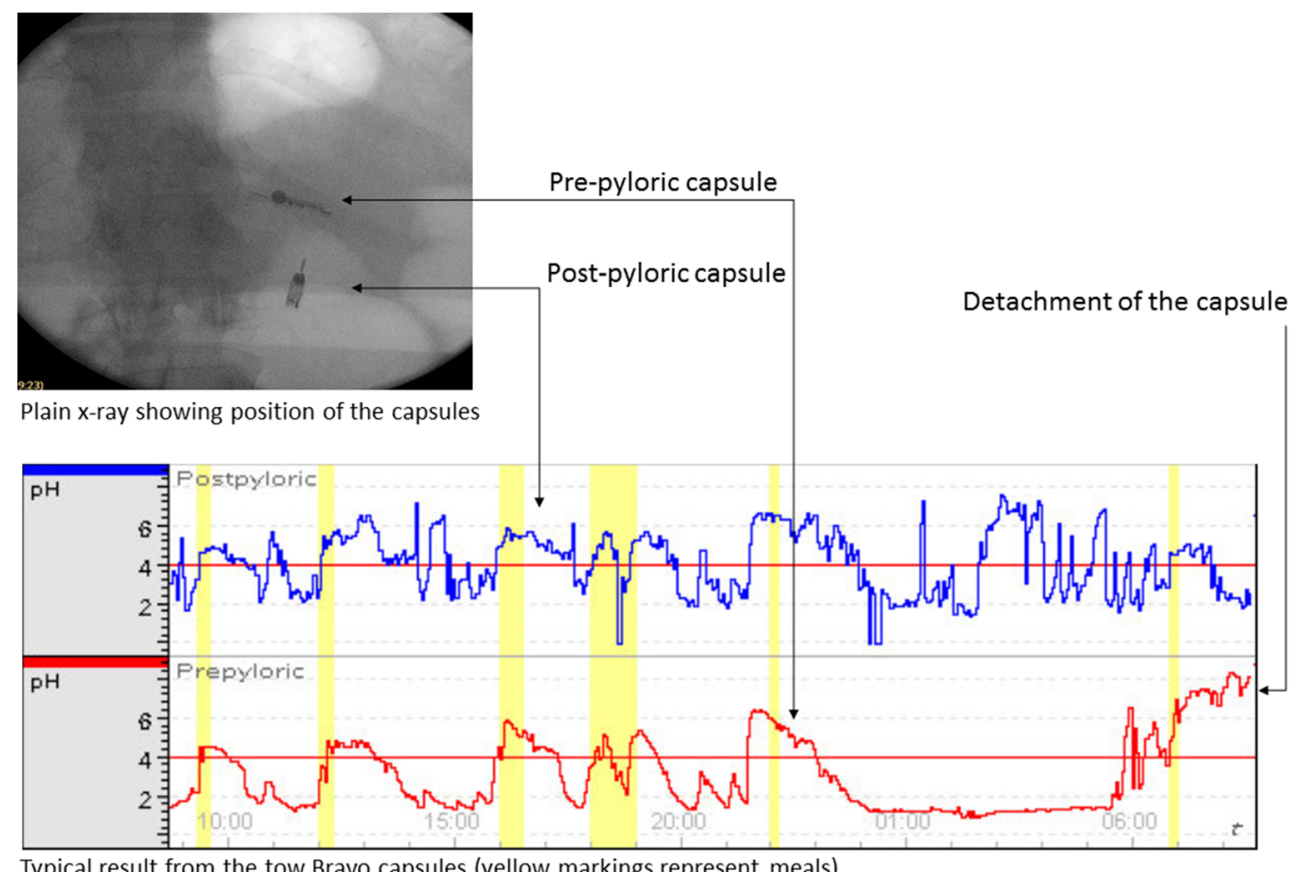

Typical result from the tow Bravo capsules (yellow markings represent meals) 
Table 1 Registration time and $\mathrm{pH}$ data, presented in median (range) and SD, in the 15 studied DS patients

\begin{tabular}{llll}
\hline & Median (range) & SD & $p$ value \\
\hline $\begin{array}{l}\text { Registration time }(h) \\
\quad\end{array}$ & $17.2(1.3-24)$ & 7.3 & \\
$\quad$ Prepyloric & $23.1(1.2-24)$ & 7.8 & 0.36 \\
$\quad$ Postpyloric & & & \\
$\mathrm{pH}$ & $2.66(1.74-5.81)$ & 1.1 & \\
$\quad$ Prepyloric & $5.79(4.75-7.58)$ & 0.9 & $<0.01$ \\
$\quad$ Postpyloric & $70.0(19.9-92.0)$ & 19.9 & \\
Percent of time with pH $<4$ & 12.3 & $<0.01$ \\
$\quad$ Prepyloric & $13.0(0.0-34.6)$ & & \\
$\quad$ Postpyloric & & 0.8 & \\
Difference in pH & $3.55(1.60-4.85)$ & 0.8 & $<0.01$ \\
$\quad$ Before meals & $1.82(0.36-3.64)$ & & \\
$\quad$ During meals & & & \\
\hline
\end{tabular}

Wilcoxon matched-pair signed rank test was used for all comparisons

endoscopic snare was very helpful. The repeated fluoroscopic examinations, directly after placing the capsule and on the following morning, verified the correct placement of the capsules.

Using only suction and the locking pin, we achieved full 24-h registration for four of the prepyloric capsules and seven postpyloric, corresponding to 26 and $50 \%$, respectively. Registration time is reported to be increased by securing the capsule onto the gastric wall by placing an endoscopic hemoclip on top of a thread tied to the capsule [11, 13, 14]. In our case, registration time was anyhow limited to $24 \mathrm{~h}$, by allowing all data from the two parallel BRAVO ${ }^{\mathrm{TM}}$-capsules to be recorded on one receiver. When using separate receivers for each capsule, registration times of up to $48 \mathrm{~h}$ onto the gastric wall has been demonstrated [12], as well as up to 4 days in the esophagus with two receivers consecutively calibrated to the same capsule [20].

In our previous measurements, just below the gastrojejunal anastomosis, in 21 RYGBP-patients, median percentage of time with $\mathrm{pH}<4$ was $10.5 \%$ [18], compared to $13.0 \%$ in the present study. Although the large gastric remnant in DS results in high acidity $(68.7 \%$ of the time with $\mathrm{pH}<4)$, the alkaline mucus produced by the Brunner's glands, located in the first few centimeters of the duodenum, manages to keep the $\mathrm{pH}$ in the small bowel on almost the same level as in RYGBP. The high amount of excreted bicarbonate ions will immediately neutralize of the majority of all gastric acid passing into the duodenum. Moreover, the mucus is known to have a protective effect against the erosive acidic gastric content on the underlying endothelium [21, 22]. Theoretically, bile reflux could also contribute to a reduced ulcer incidence, but in DS this requires a retrograde flow through $150 \mathrm{~cm}$ of the alimentary limb, which seems unlikely. Furthermore, DS has been described as an operation of choice for pathologic transpyloric duodenogastric reflux [23]. Finally, the ileal mucosa might be more resilient to acid exposure compared to the jejunum used in RYGBP, although these mechanisms remain to be elucidated.

Intragastric $\mathrm{pH}$ is affected by different factors including meals, day and night time, medication, vagotomy, presence of $H$ pylori, duodenogastric reflux, and gastrin levels [24] etc. These physiological variations have studied by both conventional $\mathrm{pH}$ measurements and measurements by the Bravo system [12, 25-27]. During fasting, $\mathrm{pH}$ is $<4$ most of the time in a healthy stomach. Ingestion of food increases the intragastric $\mathrm{pH}$ as a result of the buffering effect, usually returning to baseline after $2 \mathrm{~h}$. We could verify the change in intragastric $\mathrm{pH}$ during meals, and in addition, we could demonstrate an increase in postpyloric $\mathrm{pH}$, probably occurring due
Fig. 3 Difference in pre- and postpyloric $\mathrm{pH}$ before and during six meals
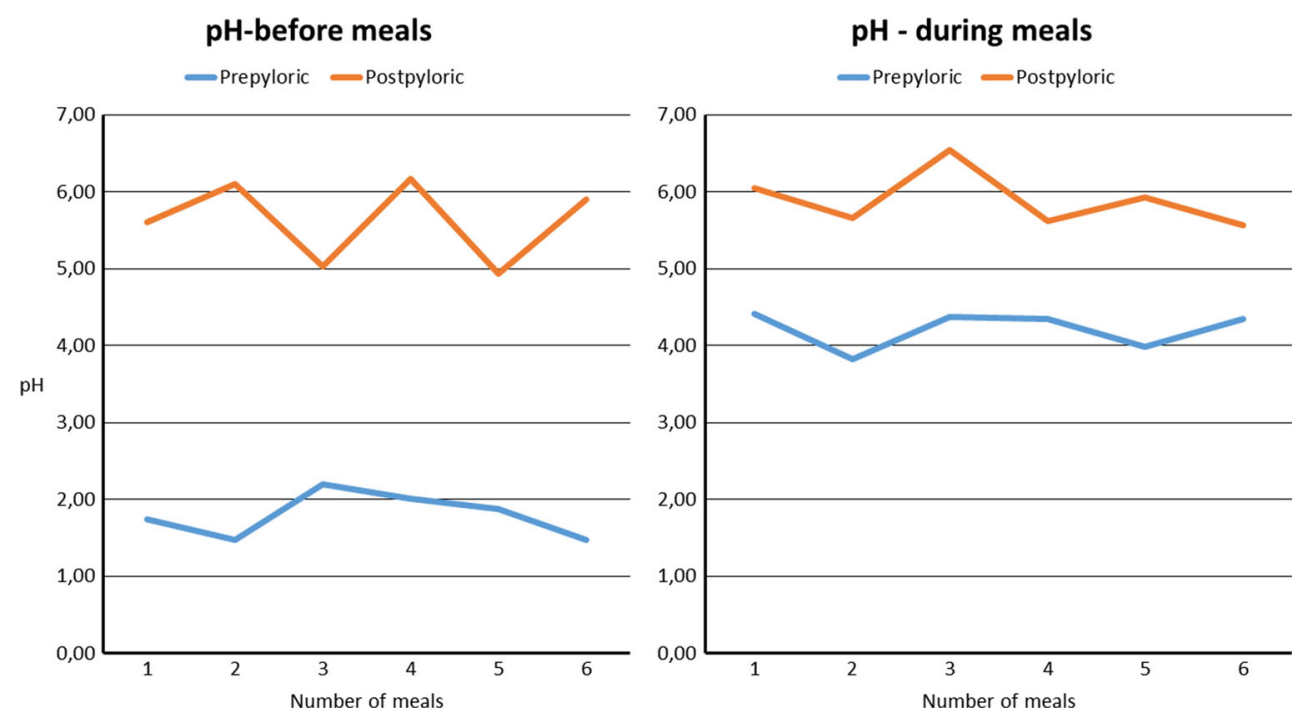
to increased buffering of ingested food passing into the duodenal bulb.

The repeated fluoroscopic examinations, directly after placing the capsule and on the following morning, verifying the exact location, are among the strengths of the present study. The possibility for patients to continue with their ordinary life, without having nasogastric catheters, and the possibility to perform detailed measurements, for example before and after meals have been favorable with the present technique. We did not achieve full 24-h registrations in all patients, which could be regarded as a weakness, especially since four patients had to be excluded from the analysis regarding $\mathrm{pH}$ difference before and during meals.

In conclusion, we could demonstrate that the duodenal bulb has a large buffering effect, thus counteracting the large amount of gastric acid passing into the small bowel after duodenal switch. This physiologic effect could contribute to the low incidence of marginal ulcers.

\section{Compliance with Ethical Standards}

The study was approved by the Regional ethical review board of Uppsala University (Dnr. 1/2007/012) and performed according to the declarations of Helsinki. All patients gave written informed consent before entering the study

Conflict of Interest The authors declare that they have no conflict of interest.

Open Access This article is distributed under the terms of the Creative Commons Attribution 4.0 International License (http:// creativecommons.org/licenses/by/4.0/), which permits unrestricted use, distribution, and reproduction in any medium, provided you give appropriate credit to the original author(s) and the source, provide a link to the Creative Commons license, and indicate if changes were made.

\section{References}

1. Sjostrom L, Narbro K, Sjostrom CD, et al. Effects of bariatric surgery on mortality in Swedish obese subjects. N Engl J Med. 2007;357(8):741-52.

2. Kendrick ML, Dakin GF. Surgical approaches to obesity. Mayo Clin Proc. 2006;81(10 Suppl):S18-24.

3. Topart P, Becouarn G, Ritz P. Weight loss is more sustained after biliopancreatic diversion with duodenal switch than Roux-en-Y gastric bypass in superobese patients. Surg Obes Relat Dis. 2013;9(4):526-30.

4. Hess DS, Hess DW, Oakley RS. The biliopancreatic diversion with the duodenal switch: results beyond 10 years. Obes Surg. 2005;15(3):408-16.

5. Sapala JA, Wood MH, Sapala MA, et al. Marginal ulcer after gastric bypass: a prospective 3 -year study of 173 patients. Obes Surg. 1998;8(5):505-16.

6. Coblijn UK, Lagarde SM, de Castro SM, et al. Symptomatic marginal ulcer disease after Roux-en-Y gastric bypass: incidence, risk factors and management. Obes Surg. 2015;25(5):805-11.
7. Lawenko RM, Lee YY. Evaluation of gastroesophageal reflux disease using the BRAVO ${ }^{\mathrm{TM}}$ capsule $\mathrm{pH}$ system. J Neurogastroenterol Motil. 2016;22(1):25-30.

8. Hess T, Hahn EG, Konturek PC. BRAVO ${ }^{\mathrm{TM}}$ wireless 48 hour $\mathrm{pH}-$ metric system. Med Sci Monit. 2009;15(1):RA17-21.

9. Wenner J, Johnsson F, Johansson J, et al. Wireless oesophageal pH monitoring: feasibility, safety and normal values in healthy subjects. Scand J Gastroenterol. 2005;40(7):768-74.

10. Ayazi S, Lipham JC, Portale G, et al. BRAVO ${ }^{\mathrm{TM}}$ catheter-free $\mathrm{pH}$ monitoring: normal values, concordance, optimal diagnostic thresholds, and accuracy. Clin Gastroenterol Hepatol. 2009;7(1):60-7.

11. Suzuki T, Yamaguchi T, Odaka T, et al. Four-day continuous gastric $\mathrm{pH}$ monitoring following anti-acid secretory drug administration: cross-over test to assess the early effects. Aliment Pharmacol Ther. 2008;27(1):66-71.

12. Yamaguchi T, Seza A, Odaka T, et al. Placement of the Bravo wireless $\mathrm{pH}$ monitoring capsule onto the gastric wall underendoscopic guidance. Gastrointest Endosc. 2006;63(7): 1046-50.

13. Chang JH, Choi MG, Yim DS, et al. A novel placement method of the $\mathrm{BRAVO}^{\mathrm{TM}}$ wireless $\mathrm{pH}$ monitoring capsule for measuring intragastric pH. Dig Dis Sci. 2009;54(3):578-85.

14. Ono S, Kato M, Ono Y, et al. New method for long-term monitoring of intragastric pH. World J Gastroenterol. 2007;13(47):6410-3.

15. Caparello $\mathrm{C}$, Bravi I, Cantù $\mathrm{P}$, et al. Traditional vs wireless intragastric $\mathrm{pH}$ monitoring: are the two techniques comparable? Neurogastroenterol Motil. 2012;24(10):951-e464.

16. Pandolfino JE, Schreiner MA, Lee TJ, et al. BRAVO ${ }^{\mathrm{TM}}$ capsule placement in the gastric cardia: a novel method for analysis of proximal stomach acid environment. Am J Gastroenterol. 2005;100(8):1721-7.

17. Tanimura T, Adachi K, Furuta K, et al. Usefulness of catheterless radiotelemetry $\mathrm{pH}$ monitoring system to examine the relationship between duodenal acidity and upper gastrointestinal symptoms. J Gastroenterol Hepatol. 2011;26(1):98-103.

18. Hedberg J, Hedenström H, Sundbom M. Wireless pH-metry at the gastrojejunostomy after Roux-en-Y gastric bypass: a novel use of the BRAVO ${ }^{\text {TM }}$ system. Surg Endosc. 2011;25(7):2302-7.

19. Sofi AA, Filipiak C, Sodeman T, et al. Comparison of esophageal placement of BRAVO ${ }^{\mathrm{TM}}$ capsule system under direct endoscopic guidance with conventional placement method. Clin Exp Gastroenterol. 2010;3:147-51.

20. Hirano I, Zhang Q, Pandolfino JE, et al. Four-day Bravo $\mathrm{pH}$ capsule monitoring with and without proton pump inhibitor therapy. Clin Gastroenterol Hepatol. 2005;3(11):1083-8.

21. Krause WJ. Brunner's glands: a structural, histochemical and pathological profile. Prog Histochem Cytochem. 2000;35(4):259-367.

22. Hall JE, Guyton AC. Guyton and Hall textbook of medical physiology. 12th ed. Philadelphia: Saunders/Elsevier; 2011.

23. Strignano P, Collard JM, Michel JM, et al. Duodenal switch operation for pathologic transpyloric duodenogastric reflux. Ann Surg. 2007;245(2):247-53.

24. Eriksen CA, Buchanan KD, Cuschieri A. Effects of sham feeding and a meal on plasma gastrin and duodenal $\mathrm{pH}$ in normal and duodenal ulcer patients. Ann Surg. 1989;209(4):411-7.

25. Barlow AP, Hinder RA, DeMeester TR, et al. Twenty-four-hour gastric luminal $\mathrm{pH}$ in normal subjects: influence of probe position, food, posture, and duodenogastric reflux. Am J Gastroenterol. 1994;89(11):2006-10.

26. McLauchlan G, Fullarton GM, Crean GP, et al. Comparison of gastric body and antral $\mathrm{pH}$ : a 24 hour ambulatory study in healthy volunteers. Gut. 1989;30(5):573-8.

27. Fackler WK, Vaezi MF, Richter JE. Ambulatory gastric pH monitoring: proper probe placement and normal values. Aliment Pharmacol Ther. 2001;15(8):1155-62. 